\title{
Influence of hauling on railway car vertical load
}

\author{
Marius-Adrian Spiroiu* \\ University POLITEHNICA of Bucharest, Department of Rolling Stock, Splaiul Independenţei 313, \\ Bucharest, Romania
}

\begin{abstract}
The aim of this paper is to investigate the effects of pitch phenomenon induced by traction process on railway cars. There are identified and analysed the vertical load variations occurring both on bogies and on axles as a result of pitch motion. It is investigated the influence on vertical supplementary loads of various parameters such as vehicle mass, speed, acceleration, vehicle dimensional data.
\end{abstract}

\section{Introduction}

The present paper investigates the effects of pitch phenomenon induced by traction process on hauled railway cars. The pitch motion - rotation about axis y - of the car body of railway vehicles is caused by the couple (torque) produced as a result of the height difference between the point of application of the traction force of the locomotive and the bogie bolster. In a similar way occurs bogie pitch - because of the height difference between the bogie bolster and the axle journal.

Pitch motion induces load variations both on vehicle's bogies and axles. These variations (loading and unloading) are undesirable on railway vehicles from the point of view of ride quality and traffic safety and have negative impact on adhesion forces, thus affecting traction (for motor vehicles) and braking processes.

Interest in studying this phenomenon is quite old - see [1] - and it still is a subject of research nowadays - see, e.g., [2], but studies have focused only on motor rail vehicles, for which the magnitude and the impact of pitch is more important - affecting mainly the traction force. Regarding the pitch effect on railway cars, it may be mentioned only the paper [3], where is evaluated the influence of braking process on vertical load variation.

In these circumstances, the present paper aim is to analyse the vertical load variations on bogies and axles caused by hauling in the case of a 4-axle passenger car with two suspension levels. The analysis takes into account the vehicle traction force, drag (resistance force) and acceleration.

\section{Vertical load variations induced by hauling process}

In Figure 1 are shown the forces acting on the railway car as a result of hauling process; there are also indicated the main geometrical parameters of interest.

\footnotetext{
${ }^{*}$ Corresponding author: marius_spiroiu@yahoo.com
} 


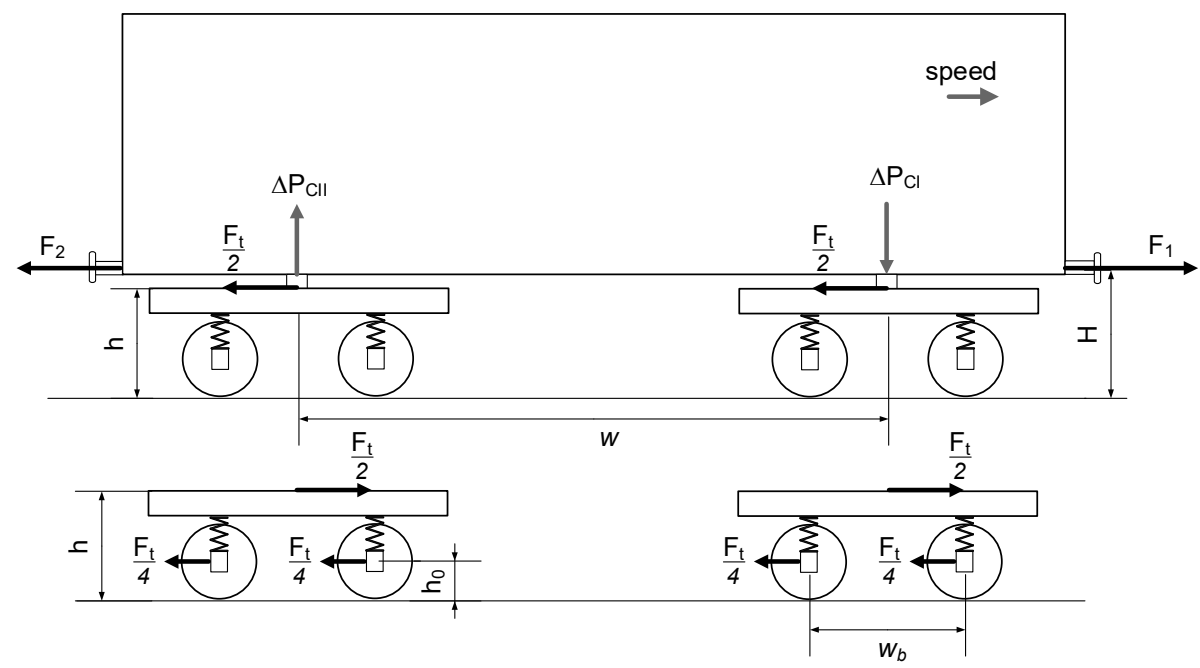

Fig. 1. Forces acting on vehicle carbody and bogies during the hauling process.

In the case of a hauled car, traction forces are provided by motor vehicle(s). The car "receives" a force $F_{1}$ from the vehicle in front and transmits a force $F_{2}$ to the vehicle behind. The difference between these two forces is the fraction of the train total traction force that is used for hauling the car:

$$
F_{t}=F_{1}-F_{2} .
$$

The equation of motion for the wagon can be written as:

$$
F_{1}-F_{2}-R_{v}=m(1+\gamma) a,
$$

where $m, a$ and $R_{v}$ are the vehicle mass, acceleration and resistance force, respectively and $\gamma$ is a mass factor modelling the effect of accelerating rotational components of the vehicle. Therefore, the car hauling force is

$$
F_{t}=F_{1}-F_{2}=R_{v}+m(1+\gamma) a .
$$

Due to the difference of elevation $(H$ versus $h$ ) between the point of application of the hauling force and the connection point between carbody and bogie, respectively, occurs a force couple (torque) which rotates the vehicle carbody about y axis, given by:

$$
C_{y c}=F_{t}(H-h)
$$

or, using equations (1) and (3),

$$
C_{y c}=\left(F_{1}-F_{2}\right)(H-h)=\left[R_{v}+m(1+\gamma) a\right](H-h) .
$$

The pitch angle of the carbody caused by the action of the torque in (5) is [4]:

$$
\varphi_{y c}=-\frac{C_{y c}}{K_{x c}},
$$

$K_{x c}$ being the carbody suspension longitudinal angular stiffness, given by [4]: 


$$
K_{x c}=\sum_{i=1}^{2} \sum_{j=1}^{2} k_{c i j} \cdot\left(x_{c i j}-x_{c 0}\right)^{2} .
$$

where $x_{c 0}$ is the $x$-coordinate of the center of motion of the vehicle carbody; $x_{c i j}$ and $k_{c i j}$ are, the $x$-coordinates and the stiffness of the bogie-carbody suspension points, respectively. Considering $k_{c}=k_{c i j}, i=1,2 ; j=1,2$, and $x_{c 11}=x_{c 12}=x_{c 1}, x_{c 21}=x_{c 22}=x_{c 2}$, the variation of vertical load on the bogies given by the rotation of vehicle carbody are:

$$
\Delta P_{C I}=2 k_{c}\left(x_{C I}-x_{c 0}\right) \varphi_{y c} ; \quad \Delta P_{C I I}=2 k_{c}\left(x_{C I I}-x_{c 0}\right) \varphi_{y c} .
$$

For $x_{c 0}=w / 2, x_{c 11}=x_{c 12}=0, x_{c 21}=x_{c 22}=w$, where $w$ is the vehicle wheelbase, the load variations $(8)$ can be written:

$$
\begin{gathered}
\Delta P_{C I}=2 k_{c}\left(0-\frac{w}{2}\right)\left(-\frac{F_{t}(H-h)}{w^{2} k_{c}}\right)=F_{t} \frac{H-h}{w}=\left[R_{v}+m(1+\gamma) a\right] \frac{H-h}{w} \\
\Delta P_{C I I}=2 k_{c}\left(w-\frac{w}{2}\right)\left(-\frac{F_{t}(H-h)}{w^{2} k_{c}}\right)=-F_{t} \frac{H-h}{w}=-\left[R_{v}+m(1+\gamma) a\right] \frac{H-h}{w} .
\end{gathered}
$$

Notice that the first bogie in the travelling direction is loaded, while the second one is unloaded.

Due to the difference in elevation (h versus $\mathrm{h}_{0}$ ) between the carbody-bogie connection point and the axle guiding system, respectively (see Figure 1), occurs a force couple (torque) which rotates the bogie about $y$ axis, given by:

$$
C_{y b}=\frac{F_{t}}{2} \cdot\left(h-h_{0}\right)
$$

under the effect of which the bogie frame is rotated by the angle

$$
\varphi_{y b}=-\frac{C_{y b}}{K_{x b}}
$$

where $K_{x b}$ is the bogie suspension longitudinal angular stiffness, given by

$$
K_{x b}=\sum_{i=1}^{2} \sum_{j=1}^{2} k_{b i j} \cdot\left(x_{b i j}-x_{b 0}\right)^{2}
$$

where $x_{b 0}$ is the $x$-coordinate of the center of motion of the bogie; $x_{b i j}$ and $k_{b i j}$ are, respectively, the $x$-coordinates and the suspension stiffness corresponding to each axle journal.

Because of the combined effect - on each bogie - of torque $C_{y b}$ and of load variations $\Delta P_{C I}$ and $\Delta P_{C I I}$, the vertical load variation for the $j$ journal of axle $i$ can be written as:

$$
\Delta P_{i j}=k_{b i j}\left\lfloor \pm f_{z}+\left(x_{b i j}-x_{b 0}\right) \cdot \varphi_{y b}\right\rfloor,
$$

where $f_{z}$ is the vertical deflection of axle suspension caused by load variations $\Delta P_{C I}$ and $\Delta P_{C I I}$ which is of opposite sign for the two bogies - see equations (9) and (10): 


$$
f_{z}=\frac{\Delta P_{C I}}{4 k_{b}}=-\frac{\Delta P_{C I I}}{4 k_{b}}=\frac{F_{t}}{4 k} \frac{H-h}{w} .
$$

Assuming that bogies are elastically and geometrically symmetric, i.e. $k_{b i j}=k_{b}, i=1,2,3$, $4 ; j=1,2 ; x_{b 11}=x_{b 12}=x_{b 1}=0, x_{b 21}=x_{b 22}=x_{b 2}=w_{b}, x_{b 31}=x_{b 32}=x_{b 3}=0, x_{b 41}=x_{b 42}=x_{b 4}=w_{b}\left(w_{b}-\right.$ bogie wheelbase) and $x_{b 0}=w_{b} / 2$, the axle journals supplementary vertical loads given by equation (14) can be written as:

$$
\begin{gathered}
\Delta P_{11}=\Delta P_{12}=k_{b}\left[\frac{F_{t}}{4 k_{b}} \frac{H-h}{w}-\left(0-\frac{w_{b}}{2}\right) \frac{F_{t}\left(h-h_{0}\right)}{2 w_{b}^{2} k_{b}}\right]=\frac{F_{t}}{4}\left(\frac{H-h}{w}+\frac{h-h_{0}}{w_{b}}\right) \\
\Delta P_{21}=\Delta P_{22}=k_{b}\left[\frac{F_{t}}{4 k_{b}} \frac{H-h}{w}-\left(w_{b}-\frac{w_{b}}{2}\right) \frac{F_{t}\left(h-h_{0}\right)}{2 w_{b}^{2} k_{b}}\right]=\frac{F_{t}}{4}\left(\frac{H-h}{w}-\frac{h-h_{0}}{w_{b}}\right) \\
\Delta P_{31}=\Delta P_{32}=k_{b}\left[-\frac{F_{t}}{4 k_{b}} \frac{H-h}{w}-\left(0-\frac{w_{b}}{2}\right) \frac{F_{t}\left(h-h_{0}\right)}{2 w_{b}^{2} k_{b}}\right]=-\frac{F_{t}}{4}\left(\frac{H-h}{w}-\frac{h-h_{0}}{w_{b}}\right) \\
\Delta P_{41}=\Delta P_{42}=k_{b}\left[-\frac{F_{t}}{4 k_{b}} \frac{H-h}{w}-\left(w_{b}-\frac{w_{b}}{2}\right) \frac{F_{t}\left(h-h_{0}\right)}{2 w_{b}^{2} k_{b}}\right]=-\frac{F_{t}}{4}\left(\frac{H-h}{w}+\frac{h-h_{0}}{w_{b}}\right)
\end{gathered}
$$

Denoting $\Delta P_{i j}=\Delta P_{i}, i=1 \ldots 4 ; j=1,2$ and taking into account equation (3):

$$
\begin{gathered}
\Delta P_{1}=\frac{R_{v}+m(1+\gamma) a}{4}\left(\frac{H-h}{w}+\frac{h-h_{0}}{w_{b}}\right) \\
\Delta P_{2}=\frac{R_{v}+m(1+\gamma) a}{4}\left(\frac{H-h}{w}-\frac{h-h_{0}}{w_{b}}\right) \\
\Delta P_{3}=\frac{R_{v}+m(1+\gamma) a}{4}\left(-\frac{H-h}{w}+\frac{h-h_{0}}{w_{b}}\right) \\
\Delta P_{4}=\frac{R_{v}+m(1+\gamma) a}{4}\left(-\frac{H-h}{w}-\frac{h-h_{0}}{w_{b}}\right)
\end{gathered}
$$

It can be seen from equations (9), (10) and (20) ... (23) that supplementary loads on bogies and axles journals induced by hauling process are directly proportional to vehicle mass, acceleration and resistance. On the other hand, it is noticeable that suspension stiffness no longer appears in the expressions of vertical forces variation. The load variation on the bogies are equal in magnitude and of opposite sense. The same situation (equal and opposite forces) occurs in the case of vertical loads on axles 1 and 4, respectively 2 and 3 . The supplementary forces also depend on the geometrical characteristics of the vehicle. In the case of the bogies, loadings are amplified by the height difference $H$ - $h$ and are decreasing when the vehicle wheelbase $w$ increases. For the axle journals loads, there are more influences, involving bogie and vehicle wheelbases and differences in elevation $H-h$ and $h$ $h_{0}$. The magnitude and sense of the supplementary forces are given by the sign of the two terms in parentheses - see equations (20) ... (23). It can be seen that the first axle has the higher loading, while the fourth has the higher unloading. Taking into account the specific 
dimensions of railway vehicles, it follows that $(H-h)<\left(h-h_{0}\right)$ and $w>w_{b}$, so the second term in parentheses is more important as magnitude.

\section{Numerical application}

In this section is considered the case of a railway passenger car with the following characteristics: $m=52000 \mathrm{~kg}, w=18 \mathrm{~m}, w_{b}=2.5 \mathrm{~m}, H=1.065 \mathrm{~m}, h=0.96 \mathrm{~m}, h_{0}=0.46 \mathrm{~m}, k_{c}=560$ $\mathrm{N} / \mathrm{mm}, k_{b}=680 \mathrm{~N} / \mathrm{mm}$. The car resistance is given by

$$
R_{v}=m r_{v}=m\left(1.65+\frac{V^{2}}{4000}\right),
$$

where $V$ is the vehicle speed in $\mathrm{km} / \mathrm{h}$ and the mass factor is considered to be $\gamma=0.03$.

It is assumed that the vehicle accelerates from 0 to $100 \mathrm{~km} / \mathrm{h}$ with a constant acceleration of $0.3 \mathrm{~m} / \mathrm{s}^{2}$.
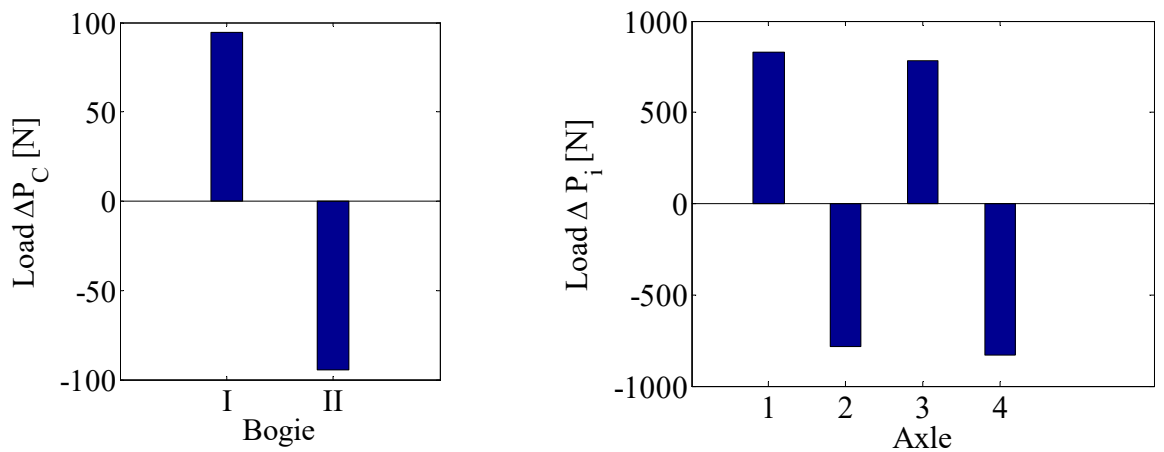

Fig. 2. Load variations on bogies (left) and on axle journals (right) for $v=20 \mathrm{~km} / \mathrm{h}, a=0.3 \mathrm{~m} / \mathrm{s}^{2}$.

In Figure 2 are presented the load variations on bogies and axles for a speed of $v=20 \mathrm{~km} / \mathrm{h}$. It can be observed that graphical representation confirms the considerations made in the previous section. Load variations are not very important as magnitude; also, it is to notice that loads on axle journals are significantly higher than the bogie ones.
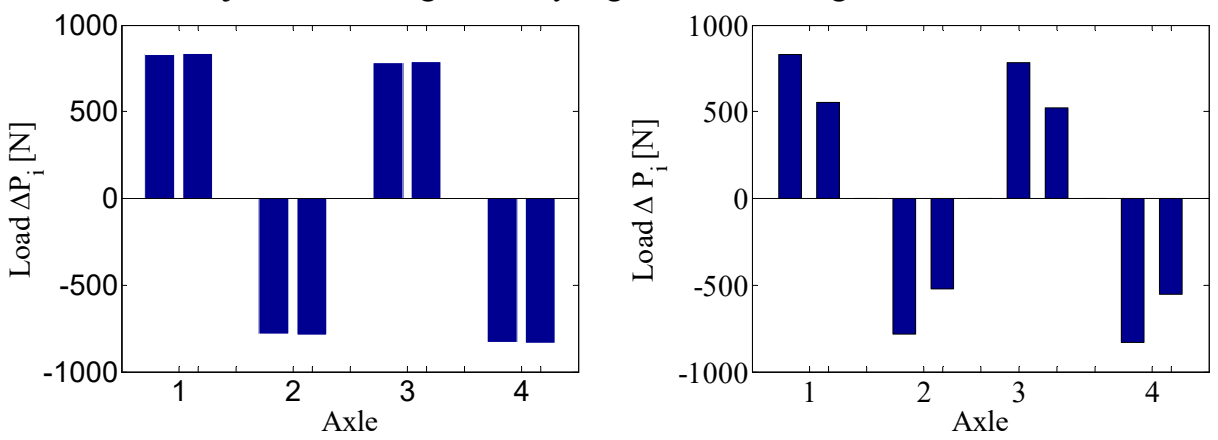

Fig. 3. Influence of vehicle speed (left) and acceleration (right) on axle journal load variations.

In Figure 3 can be observed that the influence of vehicle speed on axle journal vertical loads is negligible: increasing speed from 20 to $100 \mathrm{~km} / \mathrm{h}$ leads to an increase (in absolute value) of the supplementary forces by approximately $1 \%$. On the other hand, it can be seen that reducing the vehicle acceleration from 0.3 to $0.2 \mathrm{~m} / \mathrm{s}^{2}$ leads to a proportional reduction 
of all journal vertical loads. These influences are found equally in the case of bogies load variations.
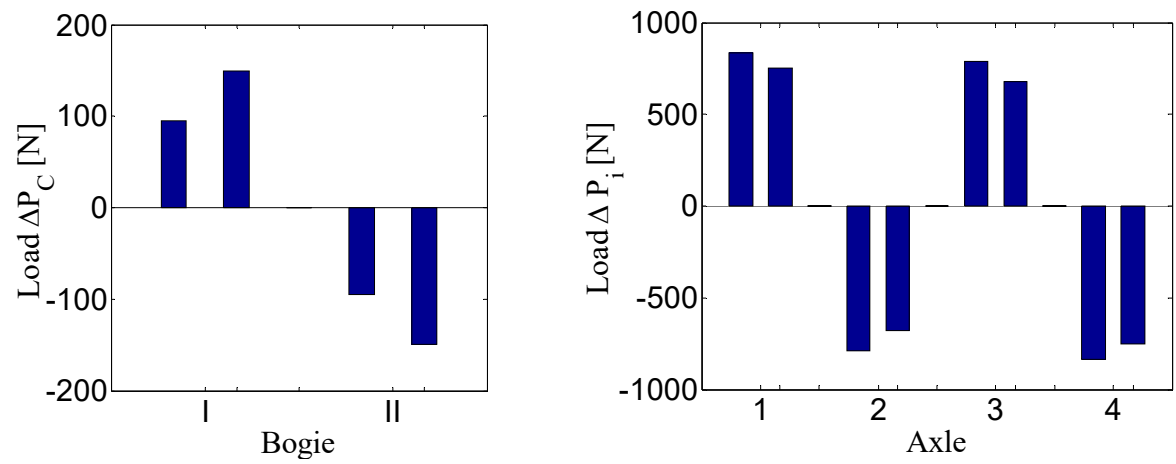

Fig. 4. Influence of carbody-bogie connection point height on bogie (left) and axle journal (right) load variations.

Geometric parameters of the vehicle have an important influence on bogie and axles load variations. A modification of the height of carbody-bogie connection point from 0.96 to 0.9 $\mathrm{m}$ has an important effect on al load variations- see Figure 4. The supplementary loads on the bogies are increasing - in absolute value, while those on the axles are reduced. This reduction is not uniform, being more accentuated in the case of axles 2 and 3 .

\section{Conclusion}

The aim of this paper was to investigate the effects of pitch phenomenon induced by hauling process on railway cars. The analysis carried out revealed that pitch motion leads to the occurrence of load variation both on bogies and on axles. The axle supplementary loads are higher than the bogies ones. The load variation on the bogies are equal in magnitude and of opposite sense, a similar situation occurs in the case of vertical loads on axles 1 and 4, respectively 2 and 3 . The first axle has the higher loading, while the fourth (last one) has the higher unloading.

The supplementary loads magnitude is not very important. For the considered usual vehicle parameters and common hauling regime, the magnitudes of load variation are below $1 \%$ of the static axle load. The supplementary loads are strongly influenced by vehicle mass and acceleration, increasing with it. On the other hand, the vehicle speed has very little impact. Of great influence are also the geometric parameters of the vehicle - wheelbases and levels of points of transmission of the traction force from the chassis to the axles. The supplementary loads on the bogies and on axle journals are increasing - in absolute value with the increase of the corresponding height differences.

\section{References}

1. G. Borgeaud, Bulletin de L'A.I. du Congrès des Chemins de Fer, 691 (1967)

2. I. Sebeșan, M. M. Călin, Civil Engineering and Urban Planning III, 493 (CRC Press 2014)

3. C. Crăciun, C. Cruceanu, M. Spiroiu, Acta Tehnica Corviniensis - Bull. of Eng., 8(2), 17 (2015)

4. G. Popa, B. Ţăruş, Supporting structures for rail vehicles (in Romanian), (Matrixrom, Bucharest, 2005) 